\title{
Valorization of Corn Seed Oil Acid Degumming Waste for Phospholipids Preparation by Phospholipase D-Mediated Processes
}

\author{
Chiara Allegretti ${ }^{1, *(\mathbb{D}}$, Andrea Bono ${ }^{1}$, Paola $\mathrm{D}^{\prime}$ Arrigo ${ }^{1,2, *(\mathbb{D}}$, Francesca Denuccio ${ }^{1,3}$, \\ Davide De Simeis $^{2}{ }^{\mathbb{D}}$, Giuseppe Di Lecce ${ }^{4}$, Stefano Serra ${ }^{2}{ }^{\mathbb{D}}$, Davide Tessaro ${ }^{1}{ }^{\circledR}$ and \\ Mariacristina Viola ${ }^{1,+}$ \\ 1 Department of Chemistry, Materials and Chemical Engineering “Giulio Natta”, Politecnico di Milano, Piazza \\ Leonardo da Vinci 32, 20133 Milano, Italy; andrea.bono@polimi.it (A.B.); f.denuccio@campus.unimib.it (F.D.); \\ davide.tessaro@polimi.it (D.T.); mariacristina.viola@polimi.it (M.V.) \\ 2 Consiglio Nazionale delle Ricerche (C.N.R.), Istituto di Scienze e Tecnologie Chimiche "Giulio Natta", \\ SCITEC, via Mancinelli 7, 20131 Milano, Italy; dav.biotec01@gmail.com (D.D.S.); stefano.serra@cnr.it (S.S.) \\ 3 Department of Biotechnology and Biosciences, University of Milano-Bicocca, 20126 Milano, Italy \\ 4 Oleificio Zucchi S.p.A., Via Acquaviva, 26100 Cremona, Italy; dirlab@oleificiozucchi.com \\ * Correspondence: chiara.allegretti@polimi.it (C.A.); paola.darrigo@polimi.it (P.D.) \\ + The authors are listed in alphabetical order.
}

Received: 19 June 2020; Accepted: 17 July 2020; Published: 21 July 2020

\begin{abstract}
This work focused on the phospholipase D-mediated treatment of the waste residue coming from acid degumming, which constitutes the second part of the degumming step in the crude corn edible oil refining process. This industrial process produces a complex by-product (called gum), a mixture containing phospholipids (PLs) whose composition depends on the nature of the oil source. This residue is usually disposed of with the consequential costs and environmental concerns. An efficient multistep protocol of physical separations of the PL-rich fraction from waste gums has been set up, including centrifugation, precipitation and solvent partitioning. This waste stream, which is thoroughly characterized after the concentration process, constitutes a renewable feedstock for the production of value-added PLs with modified polar head-exploiting phospholipase D-mediated biotransformations, which have been successfully performed on this complex natural mixture. The valorization of these waste gums through the production of high value PLs for targeted applications paves the way to a new alternative approach for their disposal, which could be of great interest from a circular economy perspective.
\end{abstract}

Keywords: phospholipase D; phospholipids; biomass valorization; transphosphatidylation; biocatalysis

\section{Introduction}

In recent years, the demand for new industrial approaches with reduced environmental impact is highly present in political agenda. In this context, the transformation of waste material, such as biomass, to high value products instead of being disposed of fits perfectly the idea of bioeconomy, as the principle guidelines of the $4 \mathrm{R}$ plan (Recover, Reduce, Reuse and Recycle) are addressed. The use of biocatalytic approaches, as well as the valorization of the structural richness already present in nature, also contributes to the process sustainability and the environmental protection for a more innovative, low-emissions economy. In a circular economy, the perspective this work aimed to valorize renewable biological resources through the investigation of a new waste exploitation strategy within the corn oil refining process for the preparation of high value phospholipids (PLs). 
PLs are amphiphilic surface active molecules, composed of two lipophilic tails and a polar head group. These molecules are the major components of all biological membranes and are biologically active compounds involved in many cellular functions [1,2]. Structurally, PL molecules present a glycerol backbone, which is esterified in positions $s n-1$ and $s n-2$ with saturated or unsaturated fatty acids and in position $s n-3$ with a phosphate diester binding the polar head. The structural diversity of these compounds is defined by the nature of the polar head, the type of fatty acid chains and their regioisomerism [3,4]. Natural PLs can be obtained from animal products, such as milk, egg yolk and krill, and from vegetable sources, such as soybeans, sunflower, corn, peanut, flaxseed, rape (canola) seed and wheatgerm [5,6]. These sources PLs are produced worldwide at a very large scale; for example, the total harvest of soybeans in 2013 was around 280 million tons and the annual world production of soybean oil was about 42 million tons [7]. Although only a small percentage (2-3\%) of this huge amount is composed of PLs, it is clearly a very abundant source of these compounds. The refining cycle of raw seed oils is generally composed of six steps: degumming, neutralization, winterization, decolourization, deodorization and clarification $[8,9]$. PLs are removed from vegetable oils during the degumming step, which can be performed by water action, acid treatment or an enzymatic procedure [10].

This work focuses on the residue of the acid treatment, which is subsequent to the water degumming step in the industrial seed oil refining. Water degumming is a gentle treatment which partially removes PLs from crude oils. During the addition of water $(1-5 \%)$ to the oil at $60-75{ }^{\circ} \mathrm{C}$, the hydration of PLs, such as phosphatidylcholine (PC) and phosphatidylinositol (PI) occurs, producing an emulsion which is stirred for 15-60 min and finally separated by centrifugation. The obtained gums, although still containing up to $30 \%$ of oil, are dried and sold as lecithins for food and industrial purposes [11,12]. The resulting oil still contains mainly non-hydratable PLs that must be removed by a subsequent acid degumming step. This method is used to achieve the total removal of PLs and is performed by adding phosphoric or citric acid at $60-90{ }^{\circ} \mathrm{C}$ to the crude oil under stirring. The salts of non-hydratable PLs, such as phosphatidylethanolamine (PE) and phosphatidic acid (PA), in these conditions become more hydrophilic and are more easily removed. The gums obtained from this process, however, can no longer be used directly as lecithin for food applications. In fact, this material is too difficult to be treated for further exploitation due to its high-water content. Furthermore, it is easily degradable, therefore not suitable for long term storage and it has to be disposed of as a special waste by the refining industry.

The outcoming fractions obtained from water and acid degumming treatments are complex mixtures of acetone-insoluble phosphatides, which chiefly consist of PC, phosphatidylserine (PS), PI and PE, combined with various amounts of other substances, such as carbohydrates, triglycerides and fatty acids. The PL composition and fatty acid profiles are highly dependent on the raw material sources from which they are obtained [13].

PLs are widely studied as they are involved in many cellular differentiation and regeneration processes, they promote the biological activity of various membrane-linked proteins and receptors, play an important role in the molecule transportation through the cell membrane and can be used as diagnostic markers for certain diseases and potential prodrugs [14-16]. Further applications include their use as surfactants, food stabilizers, natural emulsifiers and detergents $[17,18]$. The amphiphilic nature of these molecules is the key factor responsible for their unique property of spontaneous aggregation in aqueous environments: they are able to form bilayers and micelles, and this characteristic is very appealing for the drug delivery and cosmetic sector $[19,20]$. The biological activity of PLs mainly depends on the chemical identity of the polar head.

In detail, PC is involved in many digestive/metabolic functions. In the bile it is responsible for the solubilization of fatty components and cholesterol from food, it aids fat transportation between gut and liver and it is a source of acetylcholine [21].

PS, instead, is ubiquitously present in cell membranes, especially in the brain and is involved in different neurological processes. PS has a great commercial interest because it is widely exploited 
pharmaceutically as a memory and cognitive enhancer, as well as for the treatment and prevention of Alzheimer's disease [22-24].

PE has a significant function in hepatic insulin signaling and it possesses a noteworthy influence on heart health through the prevention of cellular damage by controlling the function and morphology of mammalian mitochondria and by positively regulating autophagy [25]. This PL is also a substrate for N-methyltransferase in both the eukaryotic and prokaryotic pathways, leading to the production of PC. The carboxyacyl derivatives of PE, when incorporated into liposomes, present a highly efficient conjugation to proteins, allowing these assemblies to be used as efficient drug carriers [26].

PG is another very important natural PL, which is found in microorganisms and plants and possesses important lubricant/surfactant properties when mixed with appropriate proteins. This PL is found in large amounts as a lubricant in mammalian lungs and it is widely exploited for the production of surfactant preparations for the therapeutic treatment of a variety of diseases, such as neonatal respiratory distress syndrome. PG also presents excellent liposome forming abilities, which are widely exploited for drug delivery systems [27].

Therefore, all these compounds have a great commercial value in the food, pharmaceutical and cosmetic industry, especially in relation with the purity of the products. Their preparation is challenging and can be realized by semi-synthesis or total synthesis from appropriate homochiral precursors requiring a complex sequence of protection and deprotection steps in addition to the introduction of the desired functional groups [28-30]. A biocatalytic approach aiming to prepare these specific PLs from natural sources is especially preferred when the product's destination is the food or pharmaceutical industry because of the use of harmless, natural and safer reagents [31].

Natural PC, reported in Scheme 1 as 1-palmitoyl-2-linoleyl-PC, may be modified by means of phospholipase D (PLD, E.C.3.1.4.4), an enzyme able to perform a transphosphatidylation reaction in the presence of an alcohol, which allows for the modification of the polar head [32,33], phospholipase C (PLC, E.C.3.1.4.3), which cleaves the phosphoric ester on the glycerol side [34], or by the action of phospholipases $\mathrm{A}_{1}\left(\mathrm{PLA}_{1}, 3.1 .1 .32\right)$ and $\mathrm{A}_{2}\left(\mathrm{PLA}_{2}, 3.1 .1 .4\right)$, which remove, respectively, the fatty acids in positions sn-1 and sn-2 [35].

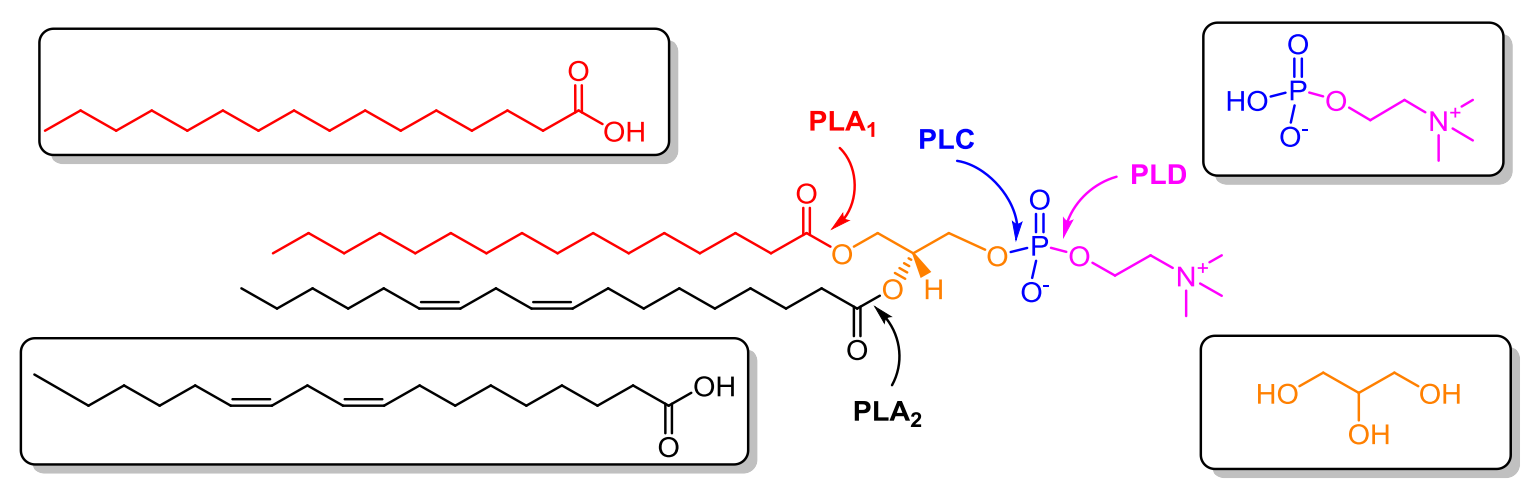

Scheme 1. General scheme describing the PC structure composed of two acyl chains, a glycerol backbone and a polar head. The enzymatic conversion possibilities that can occur on the PLs molecules are represented.

In this work the authors, taking advantage of PLD-mediated transphosphatidylations, studied the possibility to find a different fate for the waste material coming from the acid degumming of raw corn seed vegetable oil, aiming to use it as renewable feedstock for the production of value-added PLs, in order to maximize the economic value and the sustainability of the whole refining process. A fractionation process, followed by a biocatalytic procedure, has been set up to manipulate the raw material in order to transform it into functional PL-based ingredients and the downstream fraction has been fully characterized. All the enzymatic treatments of this fraction, aiming at the valorization by enrichment of the natural original mixture with a desired PL were performed on waste biomass 
from corn oil refining. In particular, three different mixtures enriched in PS, PE and PG, respectively, were prepared from the corn waste gums, through PLD-catalyzed biotransformations.

\section{Results and Discussion}

\subsection{Biomass Treatment}

In the industrial process of corn seed oil preparation, raw crude oil undergoes a refining cycle, starting with a water degumming step, which permits us to obtain an abundant mixture of PLs rich in PC and PI, which can be directly sold as lecithins without further treatment. The recovered crude oil still contains a small fraction of some PLs, and therefore it is usually subjected to a subsequent acid degumming. This process provides the crude oil fraction, which will be further refined, and a semi-solid fraction, which constitutes the waste gums that require final disposal, as shown in Figure 1A and Scheme 2A.

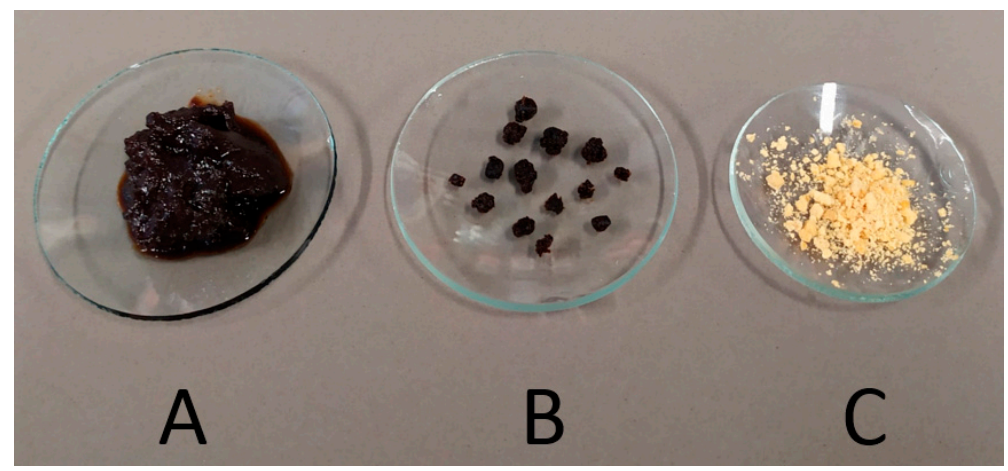

Figure 1. Pictures of the starting waste corn gums (A), the fraction BF2-S coming from the treatment process (B) and the PS-enriched BF2-S preparation (C).

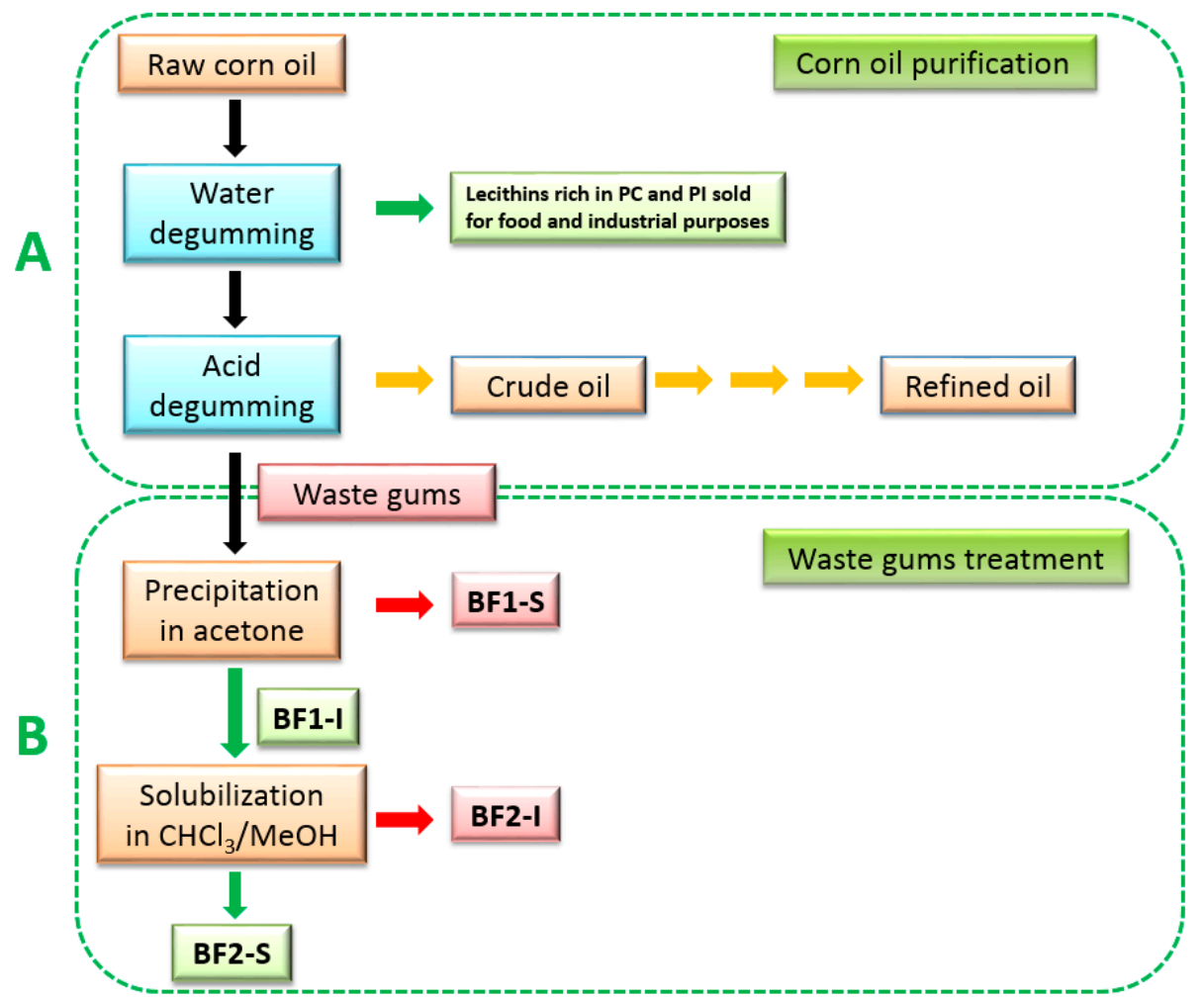

Scheme 2. Crude corn oil purification (A) and waste gums treatment scheme (B). 
The extraction of PLs from this acid degumming corn waste mixture, represented in Scheme 2B, was obtained by performing at first a precipitation step followed by a solubilization process using a mixture of solvents.

The precipitation step was performed in acetone since PLs have low solubility in this solvent, allowing the for the obtaining of a solid fraction BF1-I with a 27.5\% yield $(w / w)$. A further PL-enriched fraction was obtained by solubilizing BF1-I in a mixture of $\mathrm{CHCl}_{3} / \mathrm{CH}_{3} \mathrm{OH} 2 / 1$. From this process, the insoluble fraction BF2-I was removed by filtration, whilst the soluble fraction BF2-S, as shown in Figure 1B, was obtained with a $46 \%$ yield $(w / w)$. The total yield of recovery of BF2-S from the initial waste gums mixture was $12.7 \%(w / w)$, and the thin layer chromatography comparison between the initial waste corn gums and the final BF-2S is reported in Figure 2 with the identification of the main PLs.

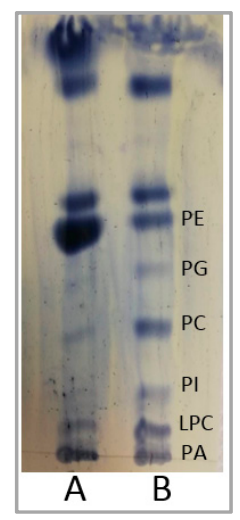

Figure 2. Thin layer chromatography of waste corn gums (lane A) and BF2-S fraction (lane B) with the identification of the main PLs (eluent $\mathrm{CHCl}_{3} / \mathrm{CH}_{3} \mathrm{OH} / \mathrm{NH}_{3}: 65 / 30 / 2.5$ ).

The phosphorus content of the initial corn degumming waste mixture and the final BF2-S fraction was evaluated, and the results are reported in Table 1.

Table 1. Phosphorus content quantification in waste corn gums and BF2-S fraction.

\begin{tabular}{cc}
\hline Sample & Phosphorus Quantification $(\mathbf{m g} / \mathbf{k g})$ \\
\hline Waste corn gums & 1093 \\
BF2-S fraction & 1619 \\
\hline
\end{tabular}

These values confirm that this treatment is efficient and leads to an enrichment in PLs of $48 \%$.

\subsection{Characterization of Fraction BF2-S}

The sample BF2-S obtained using the process described in Scheme 2 has been thoroughly analyzed in order to obtain a clear characterization of the PL compositions of the gums. ESI/MS analysis, reported in Table 2, was found to be a fundamental tool as it was able to detect the presence of lyso-phosphatidic acid (LPA), PC, lyso-phosphatidylcholine (LPC), PI, lyso-phosphatidylinositol (LPI), PG, lyso-phosphatidylglycerol (LPG) and PE. In particular, the presence of PC and LPC was observed in the positive ionization spectra, whereas PG, LPG, LPA, PI, LPI and PE could be identified in the negative ionization spectra. Furthermore, ESI/MS allowed for the identification of the major acyl chains of the PLs in the mixture showing, for the same polar head, the presence of two different PLs with different acyl chains. In fact, the PLs present in corn biomass presented mainly two characteristic pairs of acyl chains: palmitoyl/linoleoyl (16:0/18:2), molecules referred to as A in Scheme 3, and linoleoyl/oleoyl (18:2/18:1), molecules referred as B in Scheme 3, in accordance with the literature [36]. This feature can be used as a definite fingerprint of this particular seed source. The complete ESI/MS spectra are reported in Figure S1 of Supplementary Materials. 
Table 2. Results of ESI/MS analysis of BF2-S fraction.

\begin{tabular}{cccc}
\hline Identified Phospholipids & Chains $\boldsymbol{s n - 1 / s n - 2}$ & Positive $\boldsymbol{m} / \boldsymbol{z}$ & Negative $\boldsymbol{m} / \boldsymbol{z}$ \\
\hline PC-A & $16: 0 / 18: 2$ & $757.8+23$ & - \\
PC-B & $18: 2 / 18: 1$ & $783.8+23$ & - \\
2-LPC-A & $16: 0$ & $495.4+23$ & - \\
2-LPC-B & $18: 2$ & $519.5+23$ & - \\
PG-A & $16: 0 / 18: 2$ & - & 745.6 \\
PG-B & $18: 2 / 18: 0$ & - & 771.6 \\
2-LPG-B & $18: 2$ & - & 507.2 \\
PA-A & $16: 0 / 18: 2$ & - & 669.8 \\
PA-B & $18: 2 / 18: 1$ & - & 695.8 \\
2-LPA-A & $16: 0$ & - & 409.0 \\
2-LPA-B & $18: 2$ & - & 433.0 \\
PI-A & $16: 0 / 18: 2$ & - & 833.6 \\
PI-B & $18: 2 / 18: 0$ & - & 771.6 \\
2-LPI-A & $16: 0$ & - & 571.3 \\
2-LPI-B & $18: 2$ & - & 595.3 \\
PE-A & $16: 0 / 18: 2$ & - & 714.6 \\
PE-B & $18: 2 / 18: 0$ & - & 740.6 \\
\hline
\end{tabular}<smiles>CCCCCC/C=C\C/C=C\CCCCCCCCC(=O)OCCCOP(=O)([O-])OCC[N+](C)(C)C</smiles>

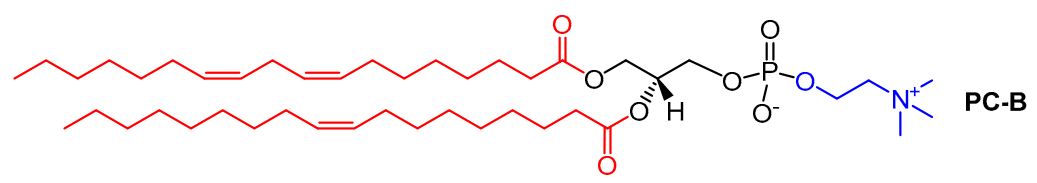<smiles>[R]C(=O)OC[C@@H](O)COP(=O)([O-])OCC[N+](C)(C)C</smiles>

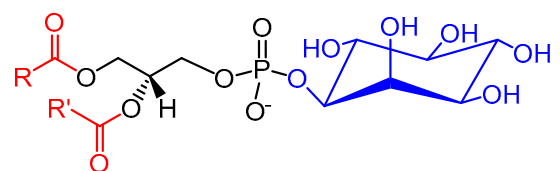

PI-A/B<smiles>[R]C(=O)OC[C@@H]([CH])OC[C@H]([2H])OP(=O)([O-])OC[C@H](O)CO</smiles>

PG-A/B<smiles>[R]C(=O)OC[C@H](O)COP(=O)([O-])OC1C(O)C(O)C2C(O)C(O)C(O)C1[C@H]2O</smiles>

2-LPI-A 2-LPI-B<smiles>[R]C(=O)OC[C@H](O)COP(=O)([O-])OC[C@H](O)COP(=O)([O-])OC[C@H](O)COC([R])=O</smiles><smiles>[R]C(=O)OC[C@@H](OC([R])=O)[C@@H]([2H])OCCCOP(=O)([O-])OCCN</smiles>

PE-A/B

Scheme 3. PLs identified in BF2-S fraction by ESI/MS (molecules named A possess a palmitic chain in position $s n-1$ and a linoleic chain in $s n-2$; molecules named B possess a linoleic chain in $s n-1$ and an oleic chain in sn-2).

Moreover, Gas Chromatographic (GC) analysis also confirmed the main components of BF2-S in terms of acyl chains, as described in ESI/MS analysis. The fatty acids quantitative composition in BF2-S is reported in Table 3, in comparison with the data relative to the raw corn oil. In accordance with the literature [37], the main acyl chain components present in the raw corn oil previous to the degumming step were the following: palmitic $(\sim 11.5 \%)$, oleic $(\sim 29.7 \%)$ and linoleic $(\sim 54.8 \%)$. Stearic and linolenic 
acids accounted just for 1.72 and $1.03 \%$, respectively, whereas the other components were detected in traces. The same trend was observed in BF2-S, where the main fatty acids were palmitic $(26.3 \%)$, oleic $(29.2 \%)$ and linoleic (39.5\%).

Table 3. Fatty acid composition of raw corn oil and BF2-S fraction (results obtained by GC analysis).

\begin{tabular}{|c|c|c|c|}
\hline \multicolumn{2}{|c|}{ Fatty Acid } & \multirow{2}{*}{$\begin{array}{c}\text { \% in Raw Corn Oil } \\
11.5\end{array}$} & \multirow{2}{*}{$\frac{\% \text { in BF2-S Fraction }}{26.3}$} \\
\hline palmitic & C16:0 & & \\
\hline palmitoleic & C16:1 & 0.17 & - \\
\hline stearic & C18:0 & 1.72 & 2.0 \\
\hline oleic & C18:1 & 29.7 & 29.2 \\
\hline linoleic & C18:2 & 54.8 & 39.5 \\
\hline linolenic & C18:3 & 1.03 & - \\
\hline arachidic & C20:0 & 0.39 & 0.30 \\
\hline eicosenoic & C20:1 & 0.33 & - \\
\hline eicosadienoic & C20:2 & 0.001 & - \\
\hline behenic acid & C22:0 & 0.11 & 0.38 \\
\hline
\end{tabular}

The HPLC analysis confirms the data obtained by the ESI/MS and adds to the previous description the quantitative composition of the identified PLs: PA 12\%, PG 24\%, PI 15\%, PE 5.4\%, PC 17\% and LPC $13 \%$. The presence of $12 \%$ PA can be explained mainly by the fact that the industrial degumming process is performed in acidic conditions which results in an easier PA extraction. Furthermore, the combination of high temperature and the presence of aqueous acids are responsible for the partial hydrolysis of PC to PA. Thirdly, the obtained gums are not very stable for hydrolysis and the amount of PA increases during stocking.

The identity of the PLs composing the BF2-S fraction has also been confirmed by ${ }^{31} \mathrm{P}$ NMR, as shown in Figure 3. The comparison between the ${ }^{31} \mathrm{P}$ NMR spectra of a standard mixture of PLs with the sample BF2-S allowed for the qualitative identification and further confirmation of the identity of the main PLs present in the gums. The attribution of the peaks of the standard mixture was performed by recording the spectrum after every single addition of a standard PL to the mixture, and this allowed for the identification of the following PLs: PC ( $\delta:-0.77 \mathrm{ppm})$, PI $(\delta:-0.39 \mathrm{ppm}), \mathrm{LPC}(\delta:-0.25 \mathrm{ppm})$, PS ( $\delta:-0.051)$, PE $(\delta: 0.02 \mathrm{ppm}), \mathrm{PG}(\delta: 0.52 \mathrm{ppm})$ and PA $(\delta: 2.06 \mathrm{ppm})$. Figure 3 shows the presence of PC, PI, LPC, PE, PG and PA in the BF2-S sample. It should be noted that the chemical shifts of PLs and, in particular, those of PA could vary between the different analyses in relation to the analyzed samples and the chemical environments, as already reported in literature $[38,39]$. That is why the attribution of the PA peak (at $\delta: 0.74 \mathrm{ppm}$ ) in the BF2-S spectrum was performed by recording a spectrum separately after the addition of PA.

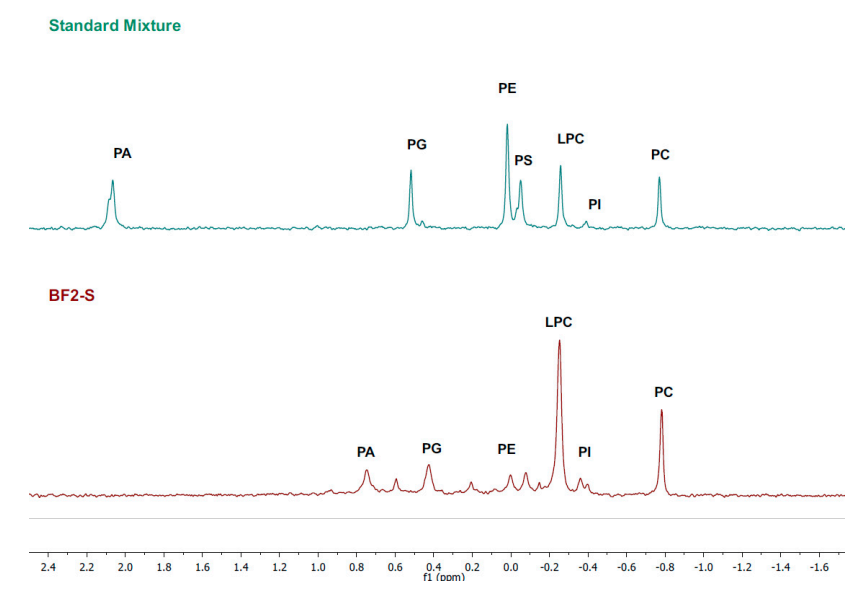

Figure 3. Comparison of ${ }^{31} \mathrm{P}$ NMR spectra of a standard mixture of PLs (green spectrum) with the BF2-S fraction (red spectrum). 


\subsection{Enrichment of PLs Mixture}

PLD is a hydrolytic enzyme which is able to transform phosphatidylcholine (PC) into phosphatidic acid (PA) through hydrolysis of the phosphate ester linkage in the polar head moiety. PC represents the natural substrate for PLD; however, it has been already observed that, with the same mechanism, PG and PE could also be transformed in polar head modified PLs in determined conditions and with appropriate nucleophiles [40,41]. In particular, when both PE and PG are in the presence of L-serine as a nucleophile, they are both converted into PS. On the other hand, when glycerol is used, PE is transformed in PG, whereas PG remains unmodified in the presence of ethanolamine.

The BF2-S fraction was submitted at first to a PLD-mediated hydrolysis of PC to PA, as shown in the upper section of Scheme 4, followed by a chromatographic purification step that allowed for the obtaining of highly pure PA, which has been valorized as a starting material for the production of phosphatidyl- $p$-nitrophenol. The latter is the reference substrate for the quantification of the PLD activity, as reported in a previous work (see Material and Methods) [42].<smiles>[R]C(=O)OCC(COP(=O)([O-])OCC[N+](C)(C)C)OC([R])=O</smiles>

PC
$\mathrm{PLD} / \mathrm{H}_{2} \mathrm{O}$ $\stackrel{\text { organic solvent }}{\longrightarrow}$

hydrolysis hydrolys

$\mathrm{X}-\mathrm{OH}=\mathrm{L}-$ serine, glycerol, ethanolamine<smiles>[X]OP(=O)([O-])OCC(COC([R])=O)OC([R])=O</smiles>

PX

Scheme 4. Phospholipase D-catalyzed transformations of PC.

In parallel, the BF2-S fraction has been also submitted to PLD-catalyzed transphosphatidylation in order to obtain a final mixture enriched in a particular PL. In fact, some PLDs from microorganisms of the Streptomyces family possess a quite unique property among hydrolytic enzymes: they are able to employ alcohols as nucleophiles instead of water, thus accomplishing the reaction of transphosphatidylation even in the presence of a predominant amount of water in a biphasic system, shown in the lower section of Scheme 4. Obviously, the presence of water leads, in some cases, to a partial hydrolysis of PC as an undesirable side reaction and the operative conditions should be carefully set in order to minimize, as much as possible, the hydrolysis product formation. In this work, the use of the PLD from Streptomyces netropsis allowed for the conversion of some natural PLs present in BF2-S into PS, PE and PG, respectively. It should be noted that LPC and PI remained unmodified in the final product mixtures.

\subsubsection{PS-Enriched BF2-S Preparation}

PS is usually obtained from natural sources, such as egg yolk, vegetable oils, soybeans and animal organs. However, the limited quantity of PS in natural sources and the low yield of the main processes of recovery hamper the efficiency of the production of this product on an industrial scale. Moreover, 
it should be pointed out that the extraction of PS from animal organs is no longer appropriate because of the possibility to transmit diseases, such as bovine spongiform encephalopathy. Therefore, the production of PS for human uses starting from raw materials of vegetal origin can be regarded as a safer process. In this work, we have performed the bioconversion of a natural mixture of PLs without previously isolating PC as it is usually reported in literature [43]. The bioconversion performed on BF2-S showed the complete disappearance not only of the natural PLD substrate PC, but also of PG and PE after $48 \mathrm{~h}$ with the concomitant formation of the desired PS-enriched BF2-S. The formation of PS was confirmed by ${ }^{31} \mathrm{P}$ NMR and ESI/MS, as shown in Figure S2 in Supplementary Materials. The composition of the final PS-enriched BF2-S is reported in Table 4. Obviously, the final yield in PS formation is highly dependent on the starting biomass composition.

Table 4. Composition of PX-enriched BF2-S compared to starting BF2-S fraction (results obtained by HPLC analysis).

\begin{tabular}{ccccc}
\hline Phospholipid & BF2-S Fraction & $\begin{array}{c}\text { PS-Enriched } \\
\text { BF2-S }\end{array}$ & $\begin{array}{c}\text { PE-Enriched } \\
\text { BF2-S }\end{array}$ & $\begin{array}{c}\text { PG-Enriched } \\
\text { BF2-S }\end{array}$ \\
\hline PA & $12 \%$ & $23 \%$ & $16 \%$ & $15 \%$ \\
PG & $24 \%$ & - & $22 \%$ & $36 \%$ \\
PI & $15 \%$ & $22 \%$ & $19 \%$ & $25 \%$ \\
PE & $5.4 \%$ & - & $15 \%$ & - \\
PC & $17 \%$ & - & - & - \\
LPC & $13 \%$ & $0.2 \%$ & $2.0 \%$ & - \\
PS & - & $9.4 \%$ & - & -5.5 \\
\hline
\end{tabular}

\subsubsection{PE-Enriched BF2-S Preparation}

The biocatalytic protocol has also been used for the production of PE, which constitutes, as reported in the Introduction, another very important PL from an economic point of view. Nowadays, PE is obtained through solvent extraction from egg yolk or soybean, although the quantity and purity cannot often satisfy the industrial demand [19]. The authors therefore envisaged the transphosphatidylation performed by PLD as a promising strategy for synthesizing PE from waste oil gums. Additionally, in this case, the complete bioconversion of PC present in BF2-S occurred, as confirmed by ${ }^{31} \mathrm{P}$ NMR and ESI/MS, as shown in Figure S3 in Supplementary Materials. In this case it should be noted that PG does not react at all with ethanolamine, as already reported in the literature [44]. The composition of the final PE-enriched BF2-S is reported in Table 4.

\subsubsection{PG-Enriched BF2-S Preparation}

Although this PL presents many appealing applications, it is difficult to be isolated from natural sources on a large scale as the quantity, which can be obtained from microorganisms and plants, is very small. The PLD-mediated enzymatic synthesis of PG is a suitable greener alternative as glycerol is mainly generated from bio-renewables as a by-product in biodiesel production, and therefore at a low cost and in large amounts $[45,46]$. The protocol previously illustrated was therefore also applied to the enrichment of the waste corn gums with PG. After $48 \mathrm{~h}$ of bioconversions, all of the initial PC and PE were completely converted into PG-enriched BF2-S, as confirmed by ${ }^{31} \mathrm{P}$ NMR and ESI/MS, as shown in Figure S4 in Supplementary Materials. The final composition of the final PG-enriched BF2-S preparation is reported in Table 4.

\section{Materials and Methods}

All chemicals were purchased from Merck (Merck Life Science S.r.l., Milan, Italy) and used without further purification. Deuterated solvents were purchased from Eurisotop (Saint-Aubin, France). The employed solvents were of analytical or HPLC grade when necessary. 
${ }^{1} \mathrm{H}$ NMR and ${ }^{31} \mathrm{P}$ NMR spectra were recorded on a $400 \mathrm{MHz}$ Bruker Avance spectrometer (Milano, Italy). Acquisition and data treatment were performed with Bruker TopSpin 3.2 software. Chemical shifts were reported in $\delta$ units (ppm), relative to tetramethylsilane (TMS) as internal standard and all spectra were recorded in $\mathrm{CDCl}_{3} / \mathrm{CD}_{3} \mathrm{OD} / \mathrm{D}_{2} \mathrm{O}$, as indicated below.

\section{1. ${ }^{31}$ P NMR Sample Preparation}

$50 \mathrm{mg}$ of the sample was dissolved with $5 \mathrm{mg}$ of triphenyl phosphate in $0.6 \mathrm{~mL}$ of a $\mathrm{CDCl}_{3}-\mathrm{CH}_{3} \mathrm{OH}$ 2:1 solution mixed with $0.4 \mathrm{~mL}$ of a CsEDTA solution. This solution was prepared by titration of $0.2 \mathrm{M}$ EDTA in $\mathrm{D}_{2} \mathrm{O}$ with $\mathrm{CsCO}_{3}$ until pH 7.6 was reached, then it was diluted 1:4 (v/v) with methanol. Vigorous stirring helped the dissolution in the case of low-solubility samples. After the complete solubilization, $0.2 \mathrm{~mL}$ of water was added and the solution was stirred again. The solution was transferred into an NMR tube and left to rest in order to achieve the correct separation of the two liquid phases. The ${ }^{31} \mathrm{P}$ uncoupled experiments were performed with the following parameters: D1: $10 \mathrm{~s}, \mathrm{SW}$ : 40 ppm, O1: -10 ppm, FID size: 32768, ns: 32, T: $320 \mathrm{~K}$.

\subsection{Thin Layer Chromatography (TLC)}

TLC plates Silica gel 60 SIL G-25 UV 254 glass $20 \times 20250 \mu \mathrm{m}$ (Macherey Nagel) were used for analytical TLC. The employed eluents (ratios reported in volume) were constituted by $\mathrm{CHCl}_{3} / \mathrm{CH}_{3} \mathrm{OH} / \mathrm{NH}_{3}$ (33\% aq.): $65 / 30 / 2.5$ or $\mathrm{CHCl}_{3} / \mathrm{CH}_{3} \mathrm{OH} / \mathrm{CH}_{3} \mathrm{COCH}_{3} / \mathrm{CH}_{3} \mathrm{COOH} / \mathrm{H}_{2} \mathrm{O}$ : 50/10/20/10/5.

Detection was performed with UV light $(254 \mathrm{~nm})$ followed by staining with $\mathrm{I}_{2}$ or cerium molibdate.

\subsection{High Performance Liquid Chromatography (HPLC)}

HPLC analyses were performed on a Merck Hitachi L4000 apparatus fitted with a Sepachrom Adamas ${ }^{\circledR}$ Silica 5 $\mu-2$ column, length/internal diameter 250/4.6 and an UV detector set to $\lambda=206 \mathrm{~nm}$. The column temperature was maintained at $35^{\circ} \mathrm{C}$. The analysis of PL mixtures was performed using isocratic mobile phase consisting of $\mathrm{CH}_{3} \mathrm{CN} / \mathrm{CH}_{3} \mathrm{OH} / \mathrm{H}_{3} \mathrm{PO}_{4}$ : 952/36/10.9 (ratios reported in volume) at a flow rate of $0.5 \mathrm{~mL} / \mathrm{min}$. All the samples were dissolved in hexane/isopropanol 1/1 with a concentration of $1 \mathrm{mg} / \mathrm{mL}$ and filtered through a $0.45 \mu \mathrm{m}$ filter.

\subsection{Column Chromatography}

Column chromatography was performed using an Automated Flash Purification Instrument PuriFlash XS 420, Column Si40 with a gradient starting from $\mathrm{CHCl}_{3} / \mathrm{CH}_{3} \mathrm{OH} 9 / 1$ to $100 \% \mathrm{CH}_{3} \mathrm{OH}$ in 25 column volumes. The operation flow was $30 \mathrm{~mL} / \mathrm{min}$.

\subsection{Gas Chromatography}

To determine the fatty acid composition in the raw corn oil and in the BF2-S sample, fatty acid methyl esters (FAMEs) were obtained by hydrolysis of the corresponding glyceride with $1 \mathrm{M} \mathrm{KOH}$ in methanol [47], and analyzed using a gas chromatograph system (GC) 7890B (Agilent, Santa Clara, California, USA). The GC instrument was equipped with a flame ionization detector (FID) and a fused silica capillary column SP 2380, (60 m length $\times 0.25 \mathrm{~mm}$ internal diameter, $0.2 \mu \mathrm{m}$ film thickness, (Supelco, St. Louis, MO, USA)). The carrier gas was helium $\left(2 \mathrm{~mL} \mathrm{~min}^{-1}\right)$; the splitting ratio was 1:80. The injector and detector temperatures were set at $250{ }^{\circ} \mathrm{C}$. The temperature program started at $150{ }^{\circ} \mathrm{C}$, was raised to $220^{\circ} \mathrm{C}$ at a constant rate of $3{ }^{\circ} \mathrm{C} \mathrm{min}^{-1}$ and was held at that temperature for $30 \mathrm{~min}$. The FAMEs were identified by comparison with known standards.

\subsection{Electrospray Ionization Mass Spectrometry}

Mass spectra were recorded on an ESI/MS Bruker Esquire 3000PLUS (ESI Ion Trap LC/MSn System, Milano, Italy), by direct infusion of a dichloromethane solution of compounds with an infusion rate of 
$4 \mu \mathrm{L} / \mathrm{min}$. Samples were analyzed using both negative and positive ionization modes to ensure the detection of all relevant compounds.

\subsection{PLD Preparation}

\subsubsection{Microorganism Fermentation}

PLD was obtained from the fermentation broth of Streptomyces netropsis DSM 40093.

The growth, the propagation and the fermentation of the strain were performed using the following medium: glucose $4 \mathrm{~g} / \mathrm{L}$; yeast extract $5 \mathrm{~g} / \mathrm{L}$; malt extract $10 \mathrm{~g} / \mathrm{L}$.

A single colony of active Streptomyces netropsis culture was picked up from a petri dish, was suspended in $1 \mathrm{~mL}$ of sterile water and was then inoculated in a $500 \mathrm{~mL}$ conical pyrex flask containing $150 \mathrm{~mL}$ of the above described medium. The flask was shaken for 5 days at $30^{\circ} \mathrm{C}$ and $140 \mathrm{rpm}$. After this period, the cells were centrifuged for $15 \mathrm{~min}\left(4^{\circ} \mathrm{C}, 4000 \mathrm{~g}\right)$ and collected, removing the medium. The cells were suspended in $10 \mathrm{~mL}$ fresh medium and were added to a sterilized fermenter vessel of a 5 L bioreactor (Biostat A BB-8822000, Sartorius Stedim, Göttingen, Germany) containing 4 L of fresh medium. The temperature, the stirring speed and the $\mathrm{pH}$ were set to $30^{\circ} \mathrm{C}, 250 \mathrm{rpm}$ and 7.0 , respectively. The $\mathrm{pH}$ was controlled by dropwise addition of sterilized aqueous solutions $(10 \% w / w$ in water) of either acetic acid or ammonia. The fermentation was performed aerobically, setting a minimum air flow of $2 \mathrm{~L} / \mathrm{min}(0.5 \mathrm{v} / \mathrm{v} / \mathrm{min})$. After $48 \mathrm{~h}$ the fermentation broth was filtered through a celite pad and the clear liquid was stored at $4{ }^{\circ} \mathrm{C}$ in dark bottles.

\subsubsection{Precipitation and Dialysis}

To $500 \mathrm{~mL}$ of the filtered broth, $215 \mathrm{~g}$ of ammonium sulphate was added over $1 \mathrm{~h}$ at $4{ }^{\circ} \mathrm{C}$ under stirring. Once the ammonium sulphate was completely dissolved, the broth was left at $4{ }^{\circ} \mathrm{C}$ overnight in order to allow for precipitation. After $23 \mathrm{~h}$, the precipitated pellet was separated from the broth by centrifugation at $8000 \mathrm{rpm}$ for $15 \mathrm{~min}$ at $4{ }^{\circ} \mathrm{C}$. The solid was then dissolved in a small amount of supernatant broth and dialyzed with a seamless cellulose tube (D0655 Sigma-Aldrich) against sodium acetate buffer $10 \mathrm{mM}$ at $\mathrm{pH}$. The dialyzed broth, which had an activity of $0.15 \mathrm{U} / \mathrm{mL}$ was used for all the bioconversions.

\subsection{PLD Activity Determination}

$360 \mathrm{mg}$ of $\mathrm{P} p \mathrm{NP}$ was dissolved in diethylether $(1 \mathrm{~mL})$ and added with $15 \mathrm{~mL}$ of $0.1 \mathrm{M}$ Tris buffer and $15 \mathrm{~mL}$ of a solution of $10 \%$ Triton X-100 in the same buffer, giving a final concentration of $16 \mathrm{mM}$. This mixture was heated gently to $60{ }^{\circ} \mathrm{C}$ until it became clear, the organic solvent was removed under reduced pressure and the solution was stored in dark vials at $-18^{\circ} \mathrm{C}$ [48].

PLD activity was determined spectrophotometrically using a UV-Vis Double Beam spectrophotometer V-730 Jasco (Jasco Europe, Cremella, Italy) in $0.05 \mathrm{M}$ Tris Buffer, $\mathrm{pH} 8$, by monitoring the hydrolysis of phosphatidyl-p-nitrophenol (PpNP) to phosphatidic acid and $p$-nitrophenol at $405 \mathrm{~nm}$ using a molar extinction coefficient of $18.450 \mathrm{~mol}^{-1} \mathrm{~L} \mathrm{~cm}^{-1}$. One unit (U) is defined as the amount of enzyme able to hydrolyze one $\mu \mathrm{mol}$ of $\mathrm{P} p \mathrm{NP}$ in $1 \mathrm{~min}$.

\subsection{Synthesis of Phosphatidyl-p-Nitrophenol}

\subsubsection{Preparation of PA}

$120 \mathrm{~mL}$ of PLD fermentation broth $(0.15 \mathrm{U} / \mathrm{mL})$ containing $0.1 \mathrm{M}$ of sodium acetate buffer and $0.1 \mathrm{M}$ of calcium chloride was adjusted to $\mathrm{pH} 5.6$ by the addition of acetic acid and was added to $2.4 \mathrm{~g}$ of corn gums BF2-S dissolved in $120 \mathrm{~mL}$ toluene. This biphasic mixture was left under magnetic stirring at $37^{\circ} \mathrm{C}$ for $48 \mathrm{~h}$, then the two phases were allowed to separate and the aqueous phase was further extracted twice with toluene. The organic phases were collected, dried with sodium sulfate and the solvent was evaporated under reduced pressure. The obtained residue was then purified 
after dissolution in $8 \mathrm{~mL}$ of $\mathrm{CH}_{2} \mathrm{Cl}_{2}$ by precipitation with acetone at $-20^{\circ} \mathrm{C}$. The precipitate was then filtered and purified further through chromatographic column by using a gradient starting from $\mathrm{CHCl}_{3} / \mathrm{CH}_{3} \mathrm{OH} 9 / 1$ to $\mathrm{CH}_{3} \mathrm{OH} 100 \%$ in 25 column volumes (yield $40 \%$ w/w).

\subsubsection{Transformation of PA in P $p$ NP}

$190 \mathrm{mg}$ of PA was dissolved in $4.3 \mathrm{~mL}$ of anhydrous pyridine and was treated with $74.6 \mathrm{mg}$ 4-nitrophenol and $291 \mathrm{mg}$ triisopropylbenzensulfonyl chloride at $0{ }^{\circ} \mathrm{C}$ under argon. The mixture was left stirring for $1 \mathrm{~h}$ at $0{ }^{\circ} \mathrm{C}$ and for $6 \mathrm{~h}$ at room temperature. The reaction was quenched by the addition of ice and water, was left for 30 min under stirring, and the solvent was removed under reduced pressure. The solid residue was dissolved in diethyl ether and washed with a saturated sodium carbonate solution. The organic solution was then dried with sodium sulfate, evaporated under reduced pressure and purified by silica column chromatography, using a gradient starting from $100 \% \mathrm{CH}_{2} \mathrm{Cl}_{2}$, reaching $\mathrm{CH}_{2} \mathrm{Cl}_{2} / \mathrm{CH}_{3} \mathrm{OH} 7 / 3$, allowed the obtainment of the desired product $\mathrm{P} p \mathrm{NP}$ with $60 \%$ yield $(w / w)$. The product was stored in dark vials at $-18{ }^{\circ} \mathrm{C}$.

\subsection{Biomass Recovery}

The recovery of the by-product was carried out at the Oleificio Zucchi, where the refining plant for crude seed oils is located (Cremona, Italy). The gums were obtained during the acid degumming stage and were recovered directly after the sedimentation of the aqueous mixtures, resulting from the centrifugation of crude oil. $\alpha$-Tocopheryl acetate was added to the sample $(1 \mathrm{~g} / \mathrm{Kg})$ before its storage at $4^{\circ} \mathrm{C}$ in order to suppress oxidation.

\subsection{Corn Waste Gums Treatment}

$150 \mathrm{~mL}$ of cold acetone $\left(-20^{\circ} \mathrm{C}\right)$ was added under vigorous stirring to $20 \mathrm{~g}$ of corn gums (recovered as described in Section 3.10) previously dissolved in $60 \mathrm{~mL}$ of $\mathrm{n}$-hexane. This mixture was left overnight at $-20{ }^{\circ} \mathrm{C}$ to allow complete PLs precipitation. The solid fraction (BF1-S) was recovered by filtration and dried under reduced pressure. This precipitation step yielded $5.5 \mathrm{~g}$ of gums enriched in PLs (yield $27.5 \% \mathrm{w} / \mathrm{w}$ ). This fraction was then added to $60 \mathrm{~mL}$ of a mixture of $\mathrm{CHCl}_{3} / \mathrm{CH}_{3} \mathrm{OH} 2 / 1$ and was left stirring for $2 \mathrm{~h}$ at room temperature. In this case, the insoluble fraction was eliminated by filtration (BF2-I), whilst the soluble fraction (BF2-S) was evaporated under reduced pressure, allowing the obtainment of $2.53 \mathrm{~g}$ of gums (yield $46 \% w / w$ on BF1-S).

\subsection{Determination of Phosphorous Content}

The total phosphorus content, expressed as $\mathrm{P}_{2} \mathrm{O}_{5}(\mathrm{mg} / \mathrm{kg})$, was determined by applying a modified standard method (ISO 13730/1999). According to the modified method, the sample (2 g) was weighed in a ceramic dish and burned in a muffle oven $\left(\sim 550^{\circ} \mathrm{C}\right)$ for $4 \mathrm{~h}$. Then, the burnt sample was collected and the ceramic plate was washed twice with water. Subsequently, the sample was subjected to acid hydrolysis, adding $5 \mathrm{~mL}$ of $37 \% \mathrm{HCl}$. The fraction was dried, cooled and $5 \mathrm{~mL}$ of $\mathrm{HNO}_{3}$ at $10 \%$ was added. Finally, the sample was transferred to a $25 \mathrm{~mL}$ flask and $10 \mathrm{~mL}$ of complexing solution, consisting of ammonium heptamolybdate and ammonium monovanadate, was added. A yellow vanadomolybophosphoric acid complex was obtained and the absorbance was measured at $\lambda=430 \mathrm{~nm}$ by a UV-Vis spectrophotometer (UV/Vis Lambda 365, Perkin Elmer, Waltham, Massachusetts, US), using a previously prepared blank as reference. The phosphorus content was obtained through a calibration curve.

\subsection{Preparation of $P X$-enriched BF2-S}

$15 \mathrm{~mL}$ of PLD fermentation broth $(0.15 \mathrm{U} / \mathrm{mL})$, containing $0.1 \mathrm{M}$ of sodium acetate buffer, $0.1 \mathrm{M}$ of calcium chloride and X-OH (L-serine $3 \mathrm{M}$ at pH 4.5, ethanolamine $2 \mathrm{M}$ at $\mathrm{pH} 5.6$, glycerol $8 \mathrm{M}$ at $\mathrm{pH}$ 5.6 for the respective PX-enriched BF2-S preparations) were added under vigorous magnetic stirring 
to $300 \mathrm{mg}$ of BF2-S dissolved in $15 \mathrm{~mL}$ of toluene. The reaction was left under stirring at $37^{\circ} \mathrm{C}$ for $48 \mathrm{~h}$. Then, the two phases were allowed to separate, and the aqueous phase was extracted twice with toluene. The organic phases were collected, dried with sodium sulfate and the solvent was evaporated under reduced pressure. The obtained sample was then purified, after dissolution in $1 \mathrm{~mL}$ of $\mathrm{CH}_{2} \mathrm{Cl}_{2}$, by precipitation in acetone at $-20^{\circ} \mathrm{C}$. The precipitate was then filtered, dried and the final product mixture was recovered and analyzed as indicated below:

PS-enriched BF2-S contained 9.4\% of PS (estimated by HPLC-UV)—HPLC ( $t_{\mathrm{R}} 5.58 \mathrm{~min}$ ); ESI/MS 16:0/18:2-PS [758.6] $]^{-}, 18: 2 / 18: 1-P S$ [784.6] $]^{-}{ }^{31}$ P NMR $\delta:-0.05$ ppm.

PE-enriched BF2-S contained 15\% of PE (estimated by HPLC-UV)—HPLC ( $t_{R} 6.84 \mathrm{~min}$ ), ESI MS 16:0/18:2-PE [714.6] ${ }^{-}, 18: 2 / 18: 1-\mathrm{PE}[740.6]^{-} ;{ }^{31} \mathrm{P}$ NMR $8: 0.02 \mathrm{ppm}$.

PG-enriched BF2-S contained 36\% of PG (estimated by HPLC-UV)-HPLC ( $t_{R} 2.37 \mathrm{~min}$ ), ESI/MS 16:0/18:2-PG [745.6] $]^{-}, 18: 2 / 18: 1-P G ~[771.6]^{-} ;{ }^{31}$ P NMR $\delta: 0.51$ ppm.

\section{Conclusions}

The valorization of the acid waste degumming products obtained during the industrial refining of corn oil was addressed by using a two-step procedure. The first one focused on the development of a multistep biomass treatment that allowed, starting from semi-solid raw corn gums, the obtainment of an enriched PL fraction (BF2-S), which constituted a much more suitable starting material for enzymatic biotransformations. BF2-S was submitted at first to a PLD-catalyzed hydrolysis, exploiting the PLD obtained from the fermentation of Streptomyces netropsis, followed by a careful chromatographic purification in order to obtain purified phosphatidic acid. This product was exploited for the synthesis of phosphatidyl- $p$-nitrophenol, which constitutes the substrate for a standard laboratory practical assay used for PLD activity determination. In parallel, PLD-mediated transphosphatidylation reactions were performed on the entire BF2-S fraction, allowing the obtainment of three different mixtures selectively enriched in valuable PLs. The encouraging results obtained, even with such a complex starting material, demonstrated that the protocol that has been developed is very versatile and it can be used for the production of very different PL-enriched mixtures, with the final aim of creating new products from corn seed oil waste. The valorization of these waste gum mixtures, which represent a substantial expense in corn seed oil industrial refining processes, paves the way to a new alternative approach for their disposal, which could be of great interest from a circular economy point of view.

Supplementary Materials: The following material is available online at http://www.mdpi.com/2073-4344/10/7/809/s1, Figure S1: ESI/MS analysis of BF2-S: (A) negative ions spectrum, (B) positive ions spectrum. Figure S2: ESI/MS (negative ionization) analysis of PS-enriched BF2-S mixture. Figure S3: ESI/MS (negative ionization) analysis of PE-enriched BF2-S mixture. Figure S4: ESI/MS (negative ionization) analysis of PG -enriched BF2-S mixture.

Author Contributions: Conceptualization, P.D., S.S. and D.T.; methodology, P.D., S.S. and D.T; investigation, C.A., A.B., F.D., D.D.S., G.D.L., S.S. and M.V.; resources, P.D., G.D.L., S.S. and D.T.; writing-original draft preparation, C.A.; P.D. and G.D.L.; writing-review and editing, C.A., P.D., S.S. and D.T.; funding acquisition, P.D., G.D.L., S.S. and D.T. All authors have read and agreed to the published version of the manuscript.

Funding: This research was funded by Fondazione Cariplo-INNOVHUB, project SOAVE (Seed and vegetable Oils Active Valorization through Enzymes), grant number 2017-1015.

Acknowledgments: The authors are grateful to Elisabetta Brenna for the constructive discussions about the work. The authors also wish to acknowledge Chemi Spa (Patrica, Frosinone, Italy), in particular Lorenzo de Ferra and Mauro Anibaldi, for their kind gift of PLD samples for the activity test calibration.

Conflicts of Interest: The authors declare no conflict of interest.

\section{References}

1. Dowhan, W.; Bogdanov, M.; Mileykovskaja, E. Functional Roles of Lipids in Membranes, Biochemistry of Lipids, Lipoproteins and Membranes, 5th ed.; Elsevier Science: San Diego, CA, USA, 2008; pp. 1-37.

2. D'Arrigo, P.; Servi, S. Synthesis of Lysophospholipids. Molecules 2010, 15, 1354-1377. [CrossRef]

3. David, F.; Medvedovici, A.; Sandra., P. Oils Fat and Grasses: Supercritical Fluid Chromatography; Encyclopedia of Separation Science: Kortrijk, Belgium, 2000; pp. 3567-3575. 
4. Robert, C.; Couedelo, L.; Vayesse, C.; Michalski, M.C. Vegetable lecithins: A review of their compositional diversity, impact on lipid metabolism and potential in cardiometabolic disease prevention. Biochimie 2020, 169, 121-132. [CrossRef] [PubMed]

5. Gładkowski, W.; Chojnacka, A.; Kiełbowicz, G.; Trziszka, T.; Wawrzeńczyk, C. Isolation of Pure Phospholipid Fraction from Egg Yolk. J. Am. Oil Chem. Soc. 2012, 89, 179-182. [CrossRef]

6. Weber, E.J. Compositions of commercial corn and soybean lecithins. J. Am. Oil Chem. Soc. 1981, 58, 898-901. [CrossRef]

7. Hoogevest, P.; Wendel, A. The use of natural and synthetic phospholipids as pharmaceutical excipients. Eur. J. Lipid Sci. Technol. 2014, 116, 1088-1107. [CrossRef] [PubMed]

8. Sharma, Y.C.; Yadav, M.; Upadhyay, S.N. Latest advances in degumming feedstock oils for large-scale biodiesel production. Biofuels Bioprod. Biorefin. 2019, 13, 174-191. [CrossRef]

9. Gupta, M. Practical Guide to Vegetable Oil Processing, 2nd ed.; Elsevier Science: Linwood, New Zealand, 2017; pp. 41-78.

10. Sein, A.; Hitchman, T.; Dayton, C.L. Industrial Enzyme Applications. In Enzymes in Vegetable Oil Degumming Processes; Vogel, A., May, O., Eds.; Wiley-VCH Verlag GmbH \& Co. KGaA: Weinheim, Germany, 2020; pp. 323-350. [CrossRef]

11. Kullenberg, D.; Taylor, L.A.; Schneider, M.; Massing, U. Health effects of dietary phospholipids. Lipid. Health Dis. 2012, 11, 3. [CrossRef]

12. Gładkowski, W.; Kiełbowicz, G.; Chojnacka, A.; Gil, M.; Trziszka, T.; Dobrzański, Z.; Wawrzeńczyk, C. Fatty acid composition of egg yolk phospholipid fractions following feed supplementation of Lohmann Brown hens with humic-fat preparations. Food Chem. 2011, 126, 1013-1018. [CrossRef]

13. Van Nieuwenhuyzen, W.; Tomás, M.C. Update on vegetable lecithin and phospholipid technologies. Eur. J. Lipid Sci. Technol. 2008, 110, 472-486. [CrossRef]

14. Bandu, R.; Mok, H.J.; Kim, K.P. Phospholipids as cancer biomarkers: Mass spectrometry-based analysis. Mass Spectrom. Rev. 2018, 37, 107-138. [CrossRef]

15. Gliszczyńska, A.; Niezgoda, N.; Gładkowski, W.; Świtalska, M.; Wietrzyk, J. Isoprenoid-phospholipid conjugates as potential therapeutic agents: Synthesis, characterization and antiproliferative studies. PLoS ONE 2017, 12, e0172238. [CrossRef] [PubMed]

16. Falconi, M.; Ciccone, S.; D’Arrigo, P.; Viani, F.; Sorge, R.; Novelli, G.; Patrizi, P.; Desideri, A.; Biocca, S. Design of a novel LOX-1 receptor antagonist mimicking the natural substrate. Biochem. Biophys. Res. Commun. 2013, 438, 340-345. [CrossRef]

17. Allen, T.M.; Cullis, P.R. Liposomal drug delivery systems: From concept to clinical applications. Adv. Drug Deliv. Rev. 2013, 65, 36-48. [CrossRef] [PubMed]

18. Baldassarre, F.; Allegretti, C.; Tessaro, D.; Carata, E.; Citti, C.; Vergaro, V.; Nobile, C.; Cannazza, G.; D'Arrigo, P.; Mele, A.; et al. Biocatalytic Synthesis of Phospholipids and Their Application as Coating Agents for $\mathrm{CaCO}_{3}$ Nano-crystals: Characterization and Intracellular Localization Analysis. Chem. Sel. 2016, 1, 6507-6514. [CrossRef]

19. Alavi, M.; Karimi, N.; Safaei, M. Application of Various Types of Liposomes in Drug Delivery Systems. Adv. Pharm. Bull. 2017, 7, 3-9. [CrossRef]

20. Vertzoni, M.; Markopoulos, C.; Symillides, M.; Goumas, C. Luminal lipid phases after administration of a triglyceride solution of danazol in the fed state and their contribution to the flux of danazol across Caco-2 cell monolayers. Mol. Pharm. 2012, 9, 1189-1198. [CrossRef]

21. Joensuu, M.; Wallis, T.P.; Saber, H.S.; Meunier, F.A. Phospholipases in neuronal function: A role in learning and memory. J. Neurochem. 2020, 153, 1-32. [CrossRef]

22. D'Arrigo, P.; Cerioli, L.; Chiappe, C.; Panzeri, W.; Tessaro, D.; Mele, A. Improvements in the enzymatic synthesis of phosphatidylserine employing ionic liquids. J. Mol. Catal. B Enzym. 2012, 84, 132-135. [CrossRef]

23. Kim, H.Y.; Huang, B.X.; Spector, A.A. Phosphatidylserine in the brain: Metabolism and function. Prog. Lipid Res. 2014, 56, 1-18. [CrossRef]

24. Mozzi, R.; Buratta, S.; Goracci, G. Metabolism and function of phosphatidylserine in mammalian brain. Neurochem. Res. 2003, 28, 195-214. [CrossRef]

25. Juneja, L.; Kazuoka, T.; Yamane, T.; Shimizu, S. Kinetic evaluation of conversion of phosphatidylcholine to phosphatidylethanolamine by phospholipase D from different sources. Biochim. Biophys. Acta 1988, 960, 334-341. [CrossRef] 
26. Van Der Veen, J.N.; Lingrell, S.; McCloskey, N.; LeBlond, N.D.; Galleguillos, D.; Zhao, Y.; Curtis, J.M.; Sipione, S.; Fullerton, M.D.; Vance, D.E.; et al. A role for phosphatidylcholine and phosphatidylethanolamine in hepatic insulin signaling. FASEB J. 2019, 33, 5045-5057. [CrossRef] [PubMed]

27. Mazela, J.; Merritt, T.A.; Gadzinowski, J.; Sinha, S. Evolutiom of pulmonary surfactants for the treatment of neonatal respiratory distress syndrome and paediatric lung diseases. Acta Paediatr. 2006, 95, 1036-1048. [CrossRef] [PubMed]

28. Fasoli, E.; Arnone, A.; Caligiuri, A.; D'Arrigo, P.; de Ferra, L.; Servi, S. Tin-mediated synthesis of lyso-phospholipids. Organ. Biomol. Chem. 2006, 4, 2974-2978. [CrossRef]

29. D'Arrigo, P.; Fasoli, E.; Pedrocchi-Fantoni, G.; Rossi, C.; Saraceno, C.; Servi, S.; Tessaro, D. A practical selective synthesis of mixed short/long chains glycerophosphocholines. Chem. Phys. Lipid. 2007, 147, 113-118. [CrossRef]

30. Gagnon, M.C.; Dautrey, S.; Bertrand, X.; Auger, M.; Paquin, J.F. A flexible synthetic approach to phosphatidylglycerols. Eur. J. Org. Chem. 2017, 43, 6401-6407. [CrossRef]

31. D'Arrigo, P.; Servi, S. Using phospholipases for phospholipid modification. Trends Biotechnol. 1997, 15, 90-96. [CrossRef]

32. Cerminati, S.; Paoletti, L.; Aguirre, A.; Peirú, S.; Menzella, H.G.; Castelli, M.E. Industrial uses of phospholipases: Current state and future applications. Appl. Microbiol. Biotechnol. 2019, 103, 2571-2582. [CrossRef]

33. Zhang, Z.; Chen, M.; Xu, W.; Zhang, W.; Zhang, T.; Guang, C.; Mu, W. Microbial phospholipase D: Identification, modification and application. Trends Food Sci. Technol. 2020, 96, 145-156. [CrossRef]

34. Anthonsen, T.; D’Arrigo, P.; Pedrocchi-Fantoni, G.; Secundo, F.; Servi, S.; Sundby, E. Phospholipids hydrolysis in organic solvents catalysed by immobilised phospholipase C. J. Mol. Catal. B Enzym. 1999, 6, 125-132. [CrossRef]

35. Chen, W.; Guo, W.; Gao, F. Phospholipase A1-Catalysed Synthesis of Docosahexaenoic Acid-Enriched Phosphatidylcholine in Reverse Micelles System. Appl. Biochem. Biotechnol. 2017, 182, 1037-1052. [CrossRef] [PubMed]

36. Wang, T.; White, P.J. Lipids of the Kernel. In Corn: Chemistry and Technology; Serna-Saldivar, S.O., Ed.; AACC International Press: St. Paul, MN, USA, 2018; pp. 337-368. [CrossRef]

37. Sampaio, K.A.; Zyaykina, N.; Uitterhaegen, E.; De Greyt, W.; Verhé, R.; de Almeida Meirelles, A.J.; Stevens, C.V. Enzymatic degumming of corn oil using phospholipase $C$ from a selected strain of Pichia pastoris. LWT 2019, 107, 145-150. [CrossRef]

38. Sotirhos, N.; Herslof, B.; Kenne, L. Quantitative analysis of phospholipids by ${ }^{31}$ P-NMR. J. Lipid Res. 1986, 27, 386-392. [PubMed]

39. Estrada, R.; Stolowich, N.; Yappert, M.C. Influence of temperature on ${ }^{31} \mathrm{P}$ NMR chemical shifts of phospholipids and their metabolites I. In chloroform-methanol-water. Anal. Biochem. 2008, 380, 41-50. [CrossRef]

40. Servi, S. Phospholipases as Synthetic Catalysts. In Biocatalysis_From Discovery to Application. Topics in Current Chemistry; Fessner, W.D., Ed.; Springer: Berlin/Heidelberg, Germany, 1999; pp. 127-158. [CrossRef]

41. Bossi, L.; D’Arrigo, P.; Pedrocchi-Fantoni, G.; Mele, A.; Servi, S.; Leiros, I. The substrate requirements of phospholipase D. J. Mol. Catal. B Enzym. 2001, 11, 433-438. [CrossRef]

42. Cardillo, R.; D’Arrigo, P.; De Ferra, L.; Piergianni, V.; Scarcelli, D.; Servi, S. A simple assay for the quantitative evaluation of Phospholipase D activity. Biotechnol. Tech. 1993, 7, 795-798. [CrossRef]

43. Comfurius, P.; Zwaal, R.F.A. The enzymatic synthesis of phosphatidylserine and purification by CM-cellulose column chromatography. BBA Lipid. Lipid Metab. 1977, 488, 36-42. [CrossRef]

44. D'Arrigo, P.; Pedrocchi-Fantoni, G.; Servi, S.; Strini, A. Enzyme-mediated synthesis of two diastereoisomeric forms of phosphatidylglycerol and of diphosphatidylglycerol (cardiolipin). J. Chem. Soc. Perkin Trans. 1996, 1, 2657-2660. [CrossRef]

45. Suzuri, K.; Yamamoto, Y.; Hosokawa, M.; Miyashita, K. Effect of $\alpha$-tocopherol on the synthesis of phosphatidylglycerol catalyzed by phospholipase D in an aqueous system. Biotechnol. Lett. 2009, 31, 719-723. [CrossRef]

46. Piazza, G.J.; Marmer, W.N. Conversion of phosphatidylcholine to phosphatidylglycerol with phospholipase D and glycerol. J. Am. Oil Chem. Soc. 2007, 84, 645-651. [CrossRef] 
47. Christie, W.W. Gas chromatography-mass spectrometry methods for structural analysis of fatty acids. Lipids 1998, 33, 343-353. [CrossRef] [PubMed]

48. D'Arrigo, P.; Piergianni, V.; Scarcelli, D.; Servi, S. A spectrophotometric assay for phospholipase D. Anal. Chim. Acta 1995, 304, 249-254. [CrossRef] 